\title{
WHICH MOTIVATIONAL BEHAVIORS IMPACT SUCCESS IN A CLINICAL ANATOMY COURSE FOR ENTRY LEVEL DOCTOR OF PHYSICAL THERAPY STUDENTS?
}

\author{
Philip A. Fabrizio', Anne M. R. Agur', Shannon L. Groff ${ }^{3}$ \\ ${ }^{1}$ Department of Physical Therapy, Philadelphia College of Osteopathic Medicine, Suwanee, \\ Georgia, United States of America \\ ${ }^{2}$ Division of Anatomy, Department of Surgery, University of Toronto, Toronto, Ontario, \\ Canada \\ ${ }^{3}$ Department of Education, University of St. Augustine for Health Sciences, St. Augustine, \\ Florida, United States of America
}

\begin{abstract}
Objectives: The motivational behavior of self-efficacy for learning and performance was correlated with academic success in Doctor of Physical Therapy (DPT) students taking clinical anatomy, the first foundational course in the program. Students' motivation strategies have been reported to be important factors in academic success, however, these strategies have not been investigated in DPT students. Therefore, the purpose of this study was to determine if course grade in clinical anatomy was correlated with the motivation subscales of the Motivated Strategies for Learning Questionnaire (MSLQ). Materials and Methods: The MSLQ was administered to 33 first-year DPT students who consented to participate in the study. Correlation (Pearson $r$ zero order) between the subscales and final course grade in clinical anatomy were determined. Results: Self-efficacy for learning and performance was correlated with course grade $(r(31)=.44, p<.05)$, while intrinsic and extrinsic goal orientation, task value, control of learning beliefs, and test anxiety, were poorlycorrelated. Conclusions:The results of the current study, indicating that self-efficacy for learning and performance is correlated with academic success, could be utilized in DPT programs to broaden admission processes, and aid in the development of remedial curricular and teaching strategies to support students identified with poor selfefficacy for learning and performance.
\end{abstract}

Key words: Self-efficacy; anatomy; physical therapy education

\section{RESUMEN}

Objetivos: El comportamiento motivacional de autoeficacia para el aprendizaje y el desempeño se correlacionó con el éxito académico en estudiantes de
Doctorado en Terapia Física (DPT) que tomaron anatomía clínica, el primer curso fundamental del programa. Se ha informado que las estrategias de motivación de los estudiantes son factores importantes en el éxito académico, sin embargo, estas estrategias no se han investigado en los estudiantes DPT. Por lo tanto, el propósito de este estudio fue determinar si la calificación del curso en anatomía clínica estaba correlacionada con las subescalas de motivación del Cuestionario de Estrategias Motivadas para el Aprendizaje (MSLQ). Materiales y métodos: EI MSLQ se administró a 33 estudiantes de DPT de primer año que dieron su consentimiento para participar en el estudio. Se determinó la correlación (orden cero de Pearson) entre las subescalas y la calificación final del curso en anatomía clínica. Resultados: La autoeficacia para el aprendizaje y el desempeño se correlacionó con la calificación del curso $(r \quad(31)=44, p<.05)$, mientras que la orientación a la meta intrínseca y extrínseca, el valor de la tarea, el control de las creencias de aprendizaje y la ansiedad ante los exámenes fueron escasamente correlacionados. Conclusiones: Los resultados del estudio actual, que indican que la autoeficacia para el aprendizaje y el desempeño se correlaciona con el éxito académico, podrían utilizarse en los programas de DPT para ampliar los procesos de admisión y ayudar en el desarrollo de estrategias de enseñanza y curriculares de recuperación para apoyar a los estudiantes identificados con poca autoeficacia para el aprendizaje y el desempeño.

Palabras clave: autoeficacia; anatomía; educación en fisioterapia.

\section{* Correspondence to: Prof. Philip A. Fabrizio. philipfa@pcom.edu}

Received: 31 December, 2020. Revised: 18 January, 2021, 2020. Accepted: 25 January, 2021. 


\section{INTRODUCTION}

The admissions process for Doctor of Physical Therapy (DPT) programs is designed to find applicants who have maintained high academic standards through undergraduate school, who will continue to maintain high academic standards in the DPT graduate education program and who will demonstrate excellence in the practice of physical therapy. However, reports have indicated that on average between 3.6$9.9 \%$ of students admitted into DPT programs in the United States since 2011 failed to meet the programs' academic standard and did not graduate (Commission on Accreditation in Physical Therapy Education, 2018). While the admission criteria for students entering a DPT program are based upon markers that are suggestive of previous and future academic success, such as undergraduate GPA and GRE scores, the progression from undergraduate studies to a graduate professional DPT program can be daunting (Veld et al., 2018; Wolden et al., 2020). The curricula of United States DPT programs average 88 weeks of didactic work that begins with a combination of foundational and clinical science courses (Commission on Accreditation in Physical Therapy Education, 2019). Clinical anatomy is usually the starting point of the foundational sciences curriculum, as it forms the basis for clinical understanding and problem solving (Brudvig et al., 2016; Commission on Accreditation in Physical Therapy Education, 2018). Student's motivation and cognitive strategies have been reported to be important factors in academic success (National Academy of Sciences Engineering et al., 2018; Schunk and DiBenedetto, 2020). However, the efficacy of these strategies has not been investigated at the outset of a DPT graduate education program with entry-level PT students.

Students' motivation and cognitive strategies have been reported to rely on behavioral factors including self-regulated learning (SRL), metacognition, and drive (National Academy of Sciences Engineering et al., 2018; Schunk and DiBenedetto, 2020). Self-regulated learning requires the student to be able to set goals and monitor their progress in order to make adjustments that lead to success. Metacognition has been defined as "the awareness of and knowledge about one's own thinking" (ALBaddareen et al., 2015). Metacognition requires that a student is able to reflect on their personal limitations to develop compensatory strategies that enable successful behaviors (AL-Baddareen et al., 2015; National Academy of Sciences Engineering et al., 2018). Drive, synonymous with motivation, has been described as a guiding factor that is influenced by experiences, which may help or hinder a learner's ability to achieve a goal (Ryan and Deci, 2020; Schunk and DiBenedetto, 2020). Components of motivation include intrinsic and extrinsic goal orientation, task value, control of learning beliefs, selfefficacy for learning and performance, and test anxiety (Pintrich et al., 1991; Duncan and McKeachie, 2005). Many of the behaviors and traits associated with SRL and metacognition are learnable, while those associated with motivation are rooted in the learner's beliefs. Therefore, motivation, as a set of beliefs, is a prerequisite to optimize the use of SRL and metacognition (ALBaddareen et al., 2015; National Academy of Sciences Engineering et al., 2018; Ryan and Deci, 2020; Schunk and DiBenedetto, 2020).

Current admissions criteria are largely based on GPA and GRE which are rooted in SRL and do not take into consideration student motivation. Gauging the motivation of newly admitted students in a DPT program, during their clinical anatomy course, the first foundational science course in the curriculum, may offer insight into understanding academic success. Furthermore, it would be beneficial for each student to understand how their motivation impacts their academic outcome and to identify areas of weakness and strategies for improvement. Early assessment of motivation could improve the student's academic outcomes throughout the program and provide a basis to develop broader admissions criteria.

The Motivated Strategies for Learning Questionnaire (MSLQ) has been widely used and validated for assessing learning strategies (Duncan and McKeachie, 2005). The questionnaire consists of two sections one that assesses motivation, which will be the focus of this paper, and the other that assesses SRL(Pintrich et al., 1991). The motivation section consists of subscales that assess:

- intrinsic and extrinsic goal orientation, describe the locus of goal orientation as being from within the learner or from some external source (Duncan and McKeachie, 2005; Ryan and Deci, 2020).

- task value, relates to the expectancy-value theory of motivation where the learner has determined that there is value to succeeding in the activity that outweighs the work required (Duncan and McKeachie, 2005; Eccles and Wigfield, 2020).

- control of learning beliefs, describes the learner's beliefs about whether the ability to succeed in the task is controlled by the learner or whether control is influenced by outside sources (Eccles and Wigfield, 2020; Schunk and DiBenedetto, 2020). 
- self-efficacy for learning and performance, describes a learner's beliefs about their ability to succeed and their ability to control or impact events throughout life (Bandura, 2017; Loh, 2019; Schunk and DiBenedetto, 2020).

- test anxiety, considers the negative effect that anxious behavior may have on motivation and is reverse coded compared to the other motivation subscales where a high score means increased worry (Pintrich and de Groot, 1990; Duncan and McKeachie, 2005).

Pizzimenti and Axelson (2015) reported that in an anatomy course for medical students all of the motivation subscales were correlated with academic success, with test anxiety having the highest correlation (Pizzimenti and Axelson, 2015). Further, Fournier et al., (2017) showed the test anxiety subscale, was a lone predictor of academic performance in medical students. In an undergraduate anatomy course Hensley (2014) found that both test anxiety and self-efficacy for learning and performance correlated with course grade. However, the investigation of motivation and the subscales of motivation, in firstyear DPT students is lacking. Self-directed learning and self-efficacy related to proposed abilities for working as a physical therapist were studied in physical therapy students however, the subjects were undergraduate physical therapy students and a broad set of motivation behaviors, like those assessed using the MSLQ, were not examined (van Lankveld et al., 2019). The MSLQ has not been utilized to compare motivation to academic success in the graduate level education of DPT students (Agricola et al., 2012; de Oliveira and Rodriguez-Fuentes, 2016). Further study of motivation of incoming DPT students is necessary to provide a better understanding of academic success that is not only dependent on a student's academic ability. Therefore, the purpose of this study was to determine if course grade in a Doctor of Physical Therapy program clinical anatomy course was correlated with the motivation subscales. Based on the current literature, it was hypothesized that course grade in clinical anatomy is correlated with the motivation subscales of intrinsic and extrinsic goal orientation, task value, control of learning beliefs, self-efficacy for learning and performance, and test anxiety.

\section{MATERIALS AND METHODS}

Ethics approval for this study was granted by the Institutional Review Board (IRB) of the College of Osteopathic Medicine (protocol number H19033E). There were 40 students enrolled in the firstyear DPT PT601 Clinical Anatomy course, all of whom attended an information session explaining the study presented by a department administrator. The students were also given information on where to obtain a summary of the study and consent forms if they wished to participate. Student participation was hidden from the primary investigator, who was the course director, until after course grades had been assigned. At no point did the primary investigatorspeak about the project to the students.

This postpositive relational quantitative design study sought to determine if motivational behaviors were correlated to academic success as expressed by course grade in Clinical Anatomy. The PT601 Clinical Anatomy course was a seven-credit course offered during the summer term (10 weeks) which was the first term of year one for newly admitted DPT students. The course was comprised of 156 contact hours at a ratio of two hours of lecture to 10 hours of laboratory. The lecture component of the course consisted of a variety of face-to-face teaching and learning techniques which included traditional lecture, clinical case examination, interleaving, elaborative interrogation, drawing, and flipped classroom (Sletten, 2017). The laboratory portion of the course consisted of instructor and self-guided full-body cadaver dissection with five students working as a team to dissect each specimen. Evaluation in the course was comprised of two multiple-choice written examinations (each $10 \%$ of the grade), a combination of weekly written and laboratory quizzes $(17 \%$ of the grade), a multiple-choice final examination $(17 \%$ of the grade), participation and professionalism (3\% of the grade), palpation practical examination $(17 \%$ of the grade) and two oral laboratory examinations (each $13 \%$ of the grade) the format of which has been previously described (Fabrizio, 2012). Thirty-three students consented to enroll in the study. During the third week of Clinical Anatomy, each student received an email witha Survey Monkey $\AA^{(S a n}$ Mateo, CA) link which contained questions about participant demographics and the motivation subscales of the MSLQ. The MSLQ motivation subscales have been shown to have good reliability and to be predictive of performance for college students at the course level (Pintrich et al., 1991). Validity of the MSLQ in a medical student population was initially established by Cook et al. (2011) and subsequently re-established for a modified version by Soemantri et al., (2018). The MSLQ demonstrated good internal consistency for all motivation subscales with extrinsic goal orientation and control of learning beliefs showing 
the greatest variability and the factor analysis showing a good fit for all motivation subscales (Pintrich et al., 1993). All questions were answered by students, on a seven-point Likert scale ranging from one (not at all true of me) to seven (very true of me).

Demographic information collected included the localpart of the student's college email, age, gender identification, self-reported undergraduate GPA, and the student's expected course grade. Once PT601G had been completed and the final grades submitted, the students who participated in the study were linked by computer to their student course grades, without revealing their names to the course director.

Demographic information collected included the localpart of the student's college email, age, gender identification, self-reported undergraduate GPA, and the student's expected course grade. Once PT601G had been completed and the final grades submitted, the students who participated in the study were linked by computer to their student course grades, without revealing their names to the course director.

The demographic information, course grades, and motivation subscale scores were tabulated in a Microsoft Excelfor Mac (Version 16.36, Microsoft Corp., Redmond, WA) spreadsheet. The data was analyzed using SPSS statistical package, version 25.0 (IBM Corp., Armonk, NY). Subject age, gender identification, motivation subscales (independent variable), and course grade (dependent variable), were analyzed using descriptive statistics. Normality of the distribution of the data for each independent and dependent variable was assessed. Pearson $r$ zero order correlation was used to examine the relationship between each motivation subscale (independent variable) and course grade (dependent variable).

\begin{tabular}{|c|c|c|c|c|}
\hline $\begin{array}{c}\text { Variables } \\
\text { MSLQ Subscales }(1-7) *\end{array}$ & $\begin{array}{l}\text { Mean } \\
\text { (SD) }\end{array}$ & $\begin{array}{c}\text { Range } \\
\text { (min-max) }\end{array}$ & $\begin{array}{l}\text { Skewness } \\
\text { (SEM) }\end{array}$ & $\begin{array}{l}\text { Kurtosis } \\
\text { (SEM) }\end{array}$ \\
\hline Internal Goal Orientation & $\begin{array}{l}5.48 \\
(0.83)\end{array}$ & $3-7$ & $\begin{array}{l}-0.99 \\
(0.41)\end{array}$ & $\begin{array}{l}2.04 \\
(0.80)\end{array}$ \\
\hline External Goal Orientation & $\begin{array}{l}5.30 \\
(1.03)\end{array}$ & $6-7$ & $\begin{array}{l}-0.48 \\
(0.41)\end{array}$ & $\begin{array}{l}-0.37 \\
(0.80)\end{array}$ \\
\hline Task value & $\begin{array}{l}6.75 \\
(0.36)\end{array}$ & $6-7$ & $\begin{array}{l}-1.61 \\
(0.41)\end{array}$ & $\begin{array}{l}1.77 \\
(0.80)\end{array}$ \\
\hline Control of Learning Beliefs & $\begin{array}{l}6.14 \\
(0.67)\end{array}$ & $5-7$ & $\begin{array}{l}-0.43 \\
(0.41)\end{array}$ & $\begin{array}{l}-1.15 \\
(0.80)\end{array}$ \\
\hline $\begin{array}{l}\text { Self-efficacy for Learning and } \\
\text { Performance }\end{array}$ & $\begin{array}{l}5.61 \\
(0.67)\end{array}$ & $4-7$ & $\begin{array}{l}0.10 \\
(0.41)\end{array}$ & $\begin{array}{l}0.04 \\
(0.80)\end{array}$ \\
\hline Test Anxiety & $\begin{array}{l}4.26 \\
(1.36)\end{array}$ & $2-7$ & $\begin{array}{l}0.11 \\
(0.41)\end{array}$ & $\begin{array}{l}-0.78 \\
(0.80)\end{array}$ \\
\hline
\end{tabular}

\section{RESULTS}

The demographic data of the participants indicated that the average age of the subjects was 24.73 (SD-3.10) years old, and that the sample was comprised of $51.52 \%$ females $(n=$ 17 ) and $45.45 \%$ males ( $n=15)$. The self-reported average undergraduate GPA of the subjects was $3.47(\mathrm{n}=31 ; \mathrm{SD}=.30)$.

The MSLQ data was complete with each participant providing an answer to each of the motivation subscale questions. The data for each MSLQ subscale had a normal distribution as evidenced by the skewness and kurtosis being less than three times their respective standard deviations (Table 1). The highest mean score was task value followed by self-efficacy for learning and performance. Test anxiety had the lowest mean score, consistent with the reverse coded nature of the question (Table 1). However, test anxiety had the greatest range of scores followed by internal goal orientation. Selfreported undergraduate GPA was not correlated with academic success (course grade) $(r(31)=0.06, p<.05)$.

Self-efficacy for learning and performance was the only motivation subscale that correlated significantly with course grade (academic success) with a medium correlation, $(r(31)=.44$, $p<.05)$. Test anxiety, although not significant, had the next highest correlation $(r(31)=.28, p=$ .12) with course grade. Intrinsic goal orientation, 
extrinsic goal orientation, task value, and control of learning beliefs all showed small correlation with academic success. Some motivation subscales demonstrated correlations between each other but were not related to academic success. Self-reported undergraduate GPA was not correlated with academic success (course grade) $(r(31)=0.06, p<.05)$.

\section{DISCUSSION}

This was a novel study that correlated motivation behaviors in DPT students to course grade in a clinical anatomy course. Self-efficacy for learning and performance was found to be positively correlated with course grade, indicating that determination of this motivation subscalecould be advantageous during the selection process to identify candidates who will be successful in the DPT program and during the early stages of the program to assist those students who may have lower scores.

The findings of the current study were consistent with previous literature demonstrating that selfefficacy was positively related with academic performance for medical students taking anatomy (Stegers-Jager et al., 2012; de Oliveira and Rodriguez-Fuentes, 2016; Tembo and Ngwira, 2016). Notably, most studies that have investigated SLR and motivation reported that selfefficacy for learning and performancewas a stronger indicator of academic success than SRL strategies alone (Stegers-Jager et al., 2012; Tembo and Ngwira, 2016). Further, this motivation subscale was deemed a valuable indicator of medical students who may be at risk for failing (Stegers-Jager et al., 2012).

Significant correlations were also found between the motivational subscales investigated in the current study. Self-efficacy for learning and performance was correlated with intrinsic goal orientation and with control of learning beliefs which is consistent with previous literature. These three motivational behaviors are self-driven in that control of learning beliefs and self-efficacy for learning and performance rely on the student's subjective view of their abilities based on past experiences, while intrinsic goal orientation is derived from the student's desire to learn and understand at a deeper level (Ryan and Deci, 2020; Schunk and DiBenedetto, 2020). One would expect, these motivation subscales to be interrelated because a student with a high degree of self-efficacy for learning and performance would also be guided by positive self-beliefs and a higher interest in learning (Eccles and Wigfield, 2020; Schunk and DiBenedetto, 2020).
Interestingly, test anxiety, which has been previously shown to have a strong correlation with academic success, was not correlated with course grade in the current study (Khalaila, 2015; Roick and Ringeisen, 2017). Test anxiety is proposed to develop from a series of previous failures which then become linked to a student's self-efficacy (Roick and Ringeisen, 2017; Loh, 2019; Eccles and Wigfield, 2020). Therefore, thestrong correlations between other motivation beliefs such as intrinsic goal orientation, selfefficacy for learning and performance, and control of learning beliefs lead one to believe that the students in this study possessed more positive thoughts and beliefs toward success overriding test anxiety. Thus, students with higher self-efficacy and higher self-confidence would likely have reduced test anxiety.

In contrast to previous studies, the current study did not demonstrate significant relationships between course grade and intrinsic goal orientation, extrinsic goal orientation, task value, or control of learning beliefs. Positive correlations have been noted by other authors between intrinsic goal orientation and academic performance in undergraduate Physical Therapy students(de Oliveira and Rodriguez-Fuentes, 2016), and betweenall motivation subscales and academic successin medical students (Pizzimenti and Axelson, 2015). This may be reflective of differences between medical students and DPT students, however due to the lack of studies investigating DPT graduate level student motivation, comparisons are difficult.

The results of the current study, indicating that self-efficacy for learning and performance was correlated with academic success, could be utilized to improve DPT education on several levels. These findings could be used to broaden admission policies, aid in the development of curricular and teaching strategies, and aid in student development.

On the admissions level, if self-efficacy for learning and performance can be used as an indicator of success, then DPT programs may be able to use questionnaires to assess the motivation subscale during the selection process. A self-assessment of self-efficacy for learning and performance may supplement the predictive ability of the cognitive markers examined in the admissions process for DPT education. The ability to determine which students would likely be successful in a DPT program, by using the self-efficacy for learning and performance score, could save the programs and students considerable effort, time, and financial burden (Shields and Dudley-Javoroski, 2018).

On a curricular level, the self-efficacy for learning and performance score can be used to guide 
positive changes. For example, the development of strategies that promote and support academic integration and linking subject material between courses can improve students' success. Loh (2019) suggested that self-efficacy could be improved through collaborative and team-based learning approaches, better teacher to student communication, and using consistent assessment techniques between courses. These strategies could aid in addressing academic isolation that is often seen with lower performing studentsby promoting integration with their more successful peers (Loh, 2019). Better curricular integration of weak students could lead to improvement in self-efficacy for learning and performance and as evidenced by the current study, improve academic performance.

In the broader sense, students must be given the tools to help reframe their "inner voice"and change their perception of their ability to attain success (Loh, 2019; Nolen, 2020). The motivation subscales of the MSLQ can be used to identify those students who may have a decreased selfefficacy for learning andperformance score. Faculty can then help those students who havedifficulty in self-efficacy for learning and performance adjust and improve byproviding coaching, andtimely and precise feedback. The emphasis of coaching should focus onenabling positive aspects of performance as opposed to concentrating on those that were negative (Roick and Ringeisen, 2017; Nolen, 2020; Schunk and DiBenedetto, 2020). Specifically, self -efficacy for learning and performance can be enhanced by giving students a stepwise progression of increasingly difficult tasks to promote mastery and improve self-confidence (Roick and Ringeisen, 2017).

The limitations of this study include the use of a single cohort of DPT students, a self-report questionnaire, correlational analyses, and not having data of previous anatomy courses taken by students. This pilot study focused on a single cohort of DPT students to determine if any change could be detected between motivation subscales of the MSLQ and academic success as expressed by course grade. The findings are based on the results of the MSLQ, a self-report survey which is course specific. Although the MSLQ is a self-report questionnaire, it has been validated as an assessment tool (Cook et al., 2011; Soemantri et al., 2018). It was assumed that the participants would answer each question truthfully. The correlational analysis only serves to show an association of the variables and further analysis to show the predictive ability of motivational subscales on course grade would be beneficial. Further, information providing ranking the level of anatomy education that students had received prior to entering the DPT program was not collected. Thus, some students with more anatomy education may have been biased by previous anatomy experiences while answering the questionnaire. Based on the current results, further multi-program study could provide better generalizability. Previous anatomy background should also be documented.

As conclusion, the motivational behavior of selfefficacy for learning and performance was correlated with academic success in DPT students taking Clinical Anatomy, the first foundational course in the program. This motivation subscale of the MSLQ, in addition to cognitive measures, could be advantageous for selecting candidates who are more likely to complete the DPT program successfully. Curricular and individualbehavioral strategies for students identified as having difficulty with academic performance could be implemented to improve self-efficacy for learning and performance, thereby enhancing their academic experience.

\section{Conflict of Interest/s \\ None}

\section{Funding}

Not applicable

\section{Ethical Approval}

College Institutional Review Board (IRB) protocol number H19-033E

\section{Informed Consent}

All subjects were informed of their rights to withdrawal from the study at any time and voluntarily provided informed consent pursuant with subject protections and IRB requirements.

\section{Contributions}

PAF investigation, formal analysis, writing/original draft. PAF, AMRA, and SLG conceptualization, methodology, writing / review and editing.

\section{ACKNOWLEDGEMENTS}

The authors wish to thank those people who generously donate their bodies for science and education, without whom this course and research would not take place.

\section{REFERENCES}

AL-Baddareen G, Ghaith S, Akour M. 2015. Selfefficacy, achievement goals, and metacognition 
as predictors of academic motivation. Procedia Soc Behav Sci 191:2068-2073.

Agricola BT, Blind P, Traas E. 2012. Differences in regulation and efficiency of learning between traditional and non-traditional students. Social Cosmos 3:153-169.

Bandura A. 2017. Cultivate self-efficacy for personal and organizational effectiveness. In: The Blackwell Handbook of Principles of Organization. Oxford, UK, Blackwell Publishing Ltd. p 125-141.

Brudvig TJ, Mattson DJ, Guarino AJ. 2016. Critical thinking skills and learning styles in entry-level Doctor of Physical Therapy students. JPhys Ther Educ 30:3-10.

Commission on Accreditation in Physical Therapy Education. 2019. Aggregate Program Data: 2019 Physical Therapist Education Programs Facts Sheets. $1^{\text {st }}$ Edition Alexandria, VA: Commission on Accreditation in Physical Therapy Education. 22 p. URL: http://www.capteonline.org/uploadedFiles/CAPT Eorg/About_CAPTE/Resources/Aggregate_Pro gram_Data/AggregateProgramData_PTProgra ms.pdf (accessed 26August 2020).

Cook DA, Thompson WG, Thomas KG. 2011. The Motivated Strategies for Learning Questionnaire: score validity among medicine residents. Med Educ 45:1230-1240.

de Oliveira I, Rodriguez-Fuentes G. 2016. The relationship between results on MSLQ and academic performance in different subjects of physiotherapy studies in a Spanish university. In: Gómez Chova L, López Martínez A, Candel Torres I (Editors). Proceedings of the $8^{\text {th }}$ International Conference on Education and New Learning Technologies (EDULEARN16); Barcelona, Spain, 2016 July 4-6. p 4612-4617.

Duncan TG, McKeachie WJ. 2005. The making of the motivated strategies for learning questionnaire. Educ Psychol 40:117-128.

Eccles JS, Wigfield A. 2020. From expectancyvalue theory to situated expectancy-value theory: Adevelopmental, social cognitive, and sociocultural perspective onmotivation. Contemp Educ Psychol 61:101859.

Fabrizio PA. 2012. Oral laboratory examinations in a physical therapy program. Anat Sci Educ 6:271-276.

Fournier KA, Couret J, Ramsay JB, Caulkins JL. 2017. Using collaborative two-stage examinations to address test anxiety in a large enrollment gateway course. Anat Sci Educ 10:409-422.

Hensley LC. 2014. Reconsidering active procrastination: Relations to motivation and achievement in college anatomy. Learn Individ Differ 36:157-164.
Khalaila R. 2015. The relationship between academic self-concept, intrinsic motivation, test anxiety, and academic achievement among nursing students: Mediating and moderating effects. Nurse Educ 35:432-438.

Loh EKY. 2019. What we know about expectancy-value theory, and how it helps to design a sustained motivating learning environment. System 86:102119.

National Academies of Sciences, Engineering and Medicine. 2018. How People Learn II: Learners, Contexts, and Cultures. 1st Ed. Washington, DC: National Academies Press. $328 \mathrm{p}$.

Nolen SB. 2020. A situative turn in the conversation on motivation theories. Contemp Educ Psychol 61:101866.

Pintrich PR, Smith DAF, Garcia T, McKeachie WJ. 1991. A Manual for the use of the Motivated Strategies for Learning Questionnaire (MSLQ). $1^{\text {st }}$ Ed. Ann Arbor, MI, National Center for Research to Improve Postsecondary Teaching and Learning. $76 \mathrm{p}$.

Pintrich PR, Smith DAF, Garcia T, McKeachie WJ. 1993. Reliability and predictive validity of the Motivated Strategies for Learning Questionnaire (MSLQ). Educ Psychol Meas3:801-813.

Pintrich PR, deGroot EV. 1990. Motivational and self-regulated learning components of classroom academic performance. J Educ Psychol 82:33-40.

Pizzimenti MA, Axelson RD. 2015. Assessing student engagement and self-regulated learning in a medical gross anatomy course. Anat Sci Educ 8:104-110.

Roick J, Ringeisen T. 2017. Self-efficacy, test anxiety, and academic success: A longitudinal validation. Int J Educ Res 83:84-93.

Ryan RM, Deci EL. 2020. Intrinsic and extrinsic motivation from a self-determination theory perspective: Definitions, theory, practices, and future directions. Contemp Educ Psychol 61:101860.

Schunk DH, DiBenedetto MK. 2020. Motivation and social cognitive theory. Contemp Educ Psychol 60:101832.

Shields RK, Dudley-Javoroski S. 2018. Physiotherapy education is a good financial investment, up to a certain level of student debt: An inter-professional economic analysis. J Physiother 64:183-191.

Sletten SR. 2017. Investigating flipped learning: Student self-regulated learning, perceptions, and achievement in an introductory biology course. J Sci Educ Technol 26:347-358.

Soemantri D, Mccoll G, Dodds A. 2018. Measuring medical students' reflection on their learning: Modification and validation of the 
motivated strategies for learning questionnaire (MSLQ). BMC Med Educ 18: 274.

Stegers-Jager KM, Cohen-Schotanus J, Themmen AP. 2012. Motivation, learning strategies, participation and medical school performance. Med Educ 46:678-688.

Tembo L, Ngwira F. 2016. The impact of selfefficacy beliefs on learning strategies: Towards learning human anatomy at college of medicine. J Contemp Med Educ 4:47-53.

van Lankveld $W$, Maas $M$, van Wijchen J, Visser $V$, Staal JB. 2019. Self-regulated learning in physical therapy education: A non-randomized experimental study comparing self-directed and instruction-based learning. BMC Med Educ 19:50.

Veld RV, Slaven EJ, Reynolds $B$, Shupe $P$, Woolery C. 2018. First-year doctor of physical therapy students demonstrate change in coping with stress. J Phys Ther Educ 32:138-144.

Wolden M, Hill B, VoorheesS. 2020. Predicting success for student physicaltherapists on theNational PhysicalTherapy Examination: systematicreview and meta-analysis. Phys Ther 100:73-89. 